\title{
Milliliter per Animal
}

National Cancer Institute

\section{Source}

National Cancer Institute. Milliliter per Animal. NCI Thesaurus. Code C73746.

A dose calculation unit expressed in milliliter(s) per animal. 